\title{
Advancing family medicine, improving lives
}

\section{0 in review}

\author{
Francine Lemire MDCM CCFP FCFP CAE ICD.D, EXECUTIVE DIRECTOR AND CHIEF EXECUTIVE OFFICER \\ Eric J. Mang MPA, EXECUTIVE DIRECTOR, MEMBER AND EXTERNAL RELATIONS
}

\section{Dear colleagues,}

As the year draws to a close, it is time to reflect on notable organizational accomplishments. While we have milestones and activities to celebrate College-wide, we are focusing on the CFPC advocacy achievements to validate and support the work of family physicians and family practices in a dynamic societal and practice environment. We encourage you to read our Annual Report. ${ }^{1}$

In January, we supported the Declaration of Astana, ${ }^{2}$ adding the family medicine voice in advocating for strong community-based care. In collaboration with the Canadian Medical Association (CMA) and the Royal College, we released the report of the Virtual Care Task Force in February. ${ }^{3}$ The input of the 4 working groups (interoperability and governance, licensure and quality of care, education, and payment models) remains relevant, particularly in this massive experiment we are experiencing with coronavirus disease 2019 (COVID-19). The report emphasizes the importance of virtual care in the context of an existing relationship with a most responsible provider, and of virtual care being fairly remunerated. We all experienced the effects of COVID-19 in March; like family doctors, we pivoted to working from home to ensure organizational continuity. We offered COVID-19 webinars, blogs, and up-to-date resources; the yearly mandatory reporting of Mainpro+ credits was extended by a year. In April, the Foundation for Advancing Family Medicine welcomed a \$5 million donation from the CMA Foundation to support grant applications from family physicians. More than 130 applicants submitted proposals describing rapid adaptations implemented by front-line providers to care for Canadians during a pandemic. The pluripotential nature of family practice and family doctors was highlighted in the results of a CFPC COVID-19 survey released in May. ${ }^{4}$ More than $90 \%$ of respondents expanded their scope of practice or practice environment to address the needs of people in Canada during wave 1 of the pandemic. The CFPC acknowledged in a news release how alternate payment models allowed for greater practice stability and helped to meet the complex needs of patients with chronic conditions. ${ }^{5}$ In response to social unrest south of the border, recognition of systemic racism in Canada, and the Black Lives Matter movement, the CFPC released a statement against racism in June. ${ }^{6}$

DOI: $10.46747 /$ cfp. 6612940

Cet article se trouve aussi en français à la page 939.
In July we circulated an updated evidence summary for the Patient's Medical Home vision. ${ }^{7}$ Given the ongoing robust positive evidence related to this team-based model of care, we are continuing to work with our Chapters to promote Patient's Medical Home adoption. In August we welcomed Dr Sarah Funnell, an Indigenous family physician, as a member of the CFPC Board. Meeting recommendations of the Truth and Reconciliation Commission, as well as embracing equity, diversity, and inclusion, is championed by the leadership of the CFPC. We are stronger together when we celebrate diversity. We were deeply shocked and saddened by the tragic death of Dr Walter Reynolds in Alberta.

Through then CFPC President, Dr Shirley Schipper, we advocated for a return to the bargaining table in physicians' negotiation in Alberta. We administered our emergency medicine examination to the largest candidate group ever and celebrated 35 years of the Self-Learning Program in September. With financial support from the CMA in October, we are now in the early stages of creating online professional development related to family physician and family practice resiliency. We were also pleased to welcome more than 3000 participants to our first-ever virtual Family Medicine Forum in November.

Other important milestones included the 25th anniversary of CFPC's Section of Researchers, CFP's gold National Magazine Award for Best Illustration and an increase in impact factor to 3.112 , and inroads made in protecting family medicine terminology.

As we bring 2020 to a close, we acknowledge how difficult the past year has been, professionally and personally, for many of you. We hope that you and your colleagues take time to pause, connect with family and friends (however that might look), and reflect on the positive contributions you have made in the lives of your patients and communities in this unprecedented year.

On behalf of all of us at the CFPC, our best wishes for the holiday season and 2021.

\footnotetext{
References

1. CFPC. Annual report: June 1, 2019-May 31, 2020. Mississauga, ON: CFPC; 2020.

2. Position statement in support of the Declaration of Astana. Mississauga, ON: CFPC; 2020

3. Virtual care. Recommendations for scaling up virtual medical services. Report of the Virtual Care Task Force. Canadian Medical Association, CFPC, Royal College of Physicians and Surgeons of Canada; 2020.

4. CFPC. Family physicians' response to the COVID-19 pandemic. Results of the May 2020 CFPC members survey on COVID-19. Mississauga, ON: CFPC; 2020.

5. CFPC. The need for alternative payment models in a post-COVID-19 health system. Mississauga, ON: CFPC; 2020.

6. CFPC Statement against racism. Mississauga, ON: CFPC; 2020.

7. CFPC. Evidence summary. Patient's Medical Home 2019: a new vision for family practice in Canada. Mississauga, ON: CFPC; 2020.
} 